Article

\title{
Structural Priming, Levels of Awareness, and Agency in Contact-Induced Language Change
}

\author{
Gerrit Jan Kootstra * and Pieter Muysken \\ Centre for Language Studies, Radboud University, 6525 XZ Nijmegen, The Netherlands \\ * Correspondence: g.kootstra@let.ru.nl
}

Received: 20 December 2018; Accepted: 26 July 2019; Published: 23 August 2019

check for updates

\begin{abstract}
This paper focuses on structural priming, levels of awareness, and agency in contact-induced language change, bringing insights from historical and anthropological linguistics together with psycholinguistic, processing-based approaches. We begin with a discussion of the relation between levels of awareness and agency in the linguistic literature, focusing on the work of Von Humboldt, Silverstein, Van Coetsem, and Trudgill. Then we turn to the psycholinguistic notion of structural priming, aiming to show that cross-linguistic structural priming is a plausible mechanism driving contact-induced language change, and explore the properties of priming and its relation to the levels of awareness discussion in the linguistic literature. We end with suggestions for future research to further elucidate the relation between structural priming, levels of awareness, and agency in contact-induced language change.
\end{abstract}

Keywords: structural priming; agency; awareness; interactive alignment; contact-induced language change

\section{Introduction}

A question that remains unresolved is to what extent language change can be conscious, and subject to human agency, and to what extent it takes place below the level of human awareness. This question has also been raised with respect to contact-induced language change; the contrast between two languages may be a strong trigger, also in terms of bi- and multilingual speaker awareness, and therefore the awareness issue is particularly pertinent to this kind of change. We know, for example, that there is much bilingual language play, suggesting that many speakers are aware of similarities and differences between the languages they speak (e.g., Luk 2013; Rivlina 2015; Tsiplakou 2009). Speakers make puns on word resemblances or adopt strange accents. What remains to be established is which consequences this has for actual language change.

On the other side of the spectrum, there are also many cross-linguistic processes in bilingual speakers that take place unawares. For example, without being aware of it, bilinguals are faster in producing and recognizing words that overlap in form across languages than words that do not overlap in form across languages, even in a monolingual context (e.g., Van Hell and Dijkstra 2002). Similarly, bilinguals' linguistic choices in one language can be influenced by recent exposure to another language (cross-linguistic priming; e.g., Fox 1996; Loebell and Bock 2003). This is seen as evidence that bilinguals cannot 'switch off' one of their languages; they activate both their languages in parallel (Kroll et al. 2006). This cross-language activation, which is assumed to be not under conscious control, is a prime example of language contact in the bilingual mind, and as such forms an important condition from which contact-induced language change can emerge, when this cross-language activation is sustained and continuous. Indeed, some first lines of evidence have recently emerged that indicate how patterns of cross-language activation in the minds of bilingual speakers are related to different patterns of linguistic choices made by speakers in language-contact settings compared to speakers not in language-contact settings (e.g., Fernández et al. 2017; Kootstra and Şahin 2018). 
Thus, the question of the way in which awareness and human agency play a role in contact-induced language change, and which parts of language are involved, is clearly not a settled matter. We explore this issue by bringing psycholinguistic approaches on cross-language activation and priming together with insights from historical, anthropological, and sociolinguistics. We start off with a brief discussion on levels of awareness in the linguistic literature, focusing particularly on the work of Humboldt, Silverstein, Van Coetsem and Trudgill (Section 2). We then relate this to the psychological notion of (cross-linguistic) structural priming, which has recently been proposed as a potential mechanism of (contact-induced) language change, and which at first sight involves 'unaware' language behavior, but also appears to be influenced by conscious aspects of language processing. In addition, priming as a research method is specifically designed to tap into language processing at specific levels of processing or components of language use, and thus ties in neatly with the need for a discussion about linguistic levels of awareness in the linguistic literature, and its relation to processes of language change. We discuss recent research indicating that cross-linguistic structural priming is an important mechanism in contact-induced language change (Section 3) and explore the properties of priming with respect to the relation between priming and agency and awareness (Section 4). We then conclude and offer suggestions for further research (Sections 4.4 and 5).

The goal of this paper is thus to open new potential lines of research at the intersection between linguistics and psycholinguistics. In doing so, we selectively discuss and connect seemingly disparate insights from the linguistic and psycholinguistic literature on the topic of awareness, structural priming and contact-induced language change (it is beyond the scope of this paper to provide a fully comprehensive review of the linguistic and psycholinguistic literature or to show novel empirical results to support our proposal). It should be kept in mind that the point of departure of the two approaches sketched here is rather different: the linguistic approaches depart from pragmatics and the linguistic patterns and items concerned, while the psycholinguistic approaches have cognitive processes and mechanisms as their starting point. We hope to show, however, that many of the generated linguistic hypotheses appear to converge with findings in the psycholinguistic literature, and that the priming paradigm offers a fruitful methodology to test these hypotheses.

\section{Linguistic Models on Levels of Awareness}

In this section we discuss various linguistic approaches on the concept of awareness that predate psycholinguistic work on priming, focusing particularly on levels/components of language use. Even though frequently alluded to in passing, the role of awareness in language contact research requires more focused analysis in terms of the linguistic patterns involved (see also Verschik 2017). It has been studied to some extent in first (e.g., Clark 1978) and second (e.g., Birdsong 1989) language development literature. There is also a tendency in 'third wave' variation research (Eckert 2012) to stress the role of awareness and agency in variable speech production (projecting a particular personal or group identity), but without systematic consideration of the language components involved. For this reason, to help build solid foundations for an analytic approach to this issue, we focus here on the foundational work in this area, starting with Wilhelm von Humboldt's distinction between 'inner form' and 'outer form'. We then turn to Michael Silverstein's limits of awareness model, and subsequently to Frans Van Coetsem's agency model as it relates to Silverstein's work; we end with a brief reference to sociolinguistic studies such as those of Peter Trudgill. In all cases the guiding question is: which component of language use is a speaker aware of, and of which component is (s)he not aware, in contact-induced language change?

\subsection{Humboldt's Inner Form and Outer Form}

The German philosopher and linguist von Humboldt (1836) is well known for his distinction between 'inner form' and 'outer form' in language. In his view, languages vary from each other on different levels, both in their 'inner form' - the internal conceptual organization of language, and in their 'outer form' - the outward manifestation of this organization. Components of the inner form of 
language are the more abstract components of the syntax of a language and the semantic structures. In contrast, the outer form concerns the morphology, the word inventory, the sounds of a language, and the more superficial aspects of the word order. Obviously, speakers are potentially much more aware of the outer form of language, e.g., the words and the pronunciation, than of the inner form, the conceptual organization.

The ideas developed by von Humboldt about the inner and outer forms of language became part of the American anthropological linguistics tradition through the writings of Benjamin Lee Whorf (1956), and this was the basis for the subsequent work by Silverstein.

\subsection{Silverstein's Limits of Awareness}

In his oft-cited and programmatic but rather difficult to fully comprehend Limits of Awareness paper, Silverstein (1981) has argued that several factors make successful meta-pragmatic statements possible about language (using mother-in-law speech in Australia as an example), which subsequently determine which aspects of language can easily change through conscious human agency. Agency presupposes awareness, and human agency facilitates intentional language change, as for example argued by Thomason (2006). Silverstein proposes a number of necessary, though not sufficient, conditions for an element to come above the level of awareness. Interestingly, he formulates the five key conditions as much as possible in terms of pragmatics, language use.

1. Unavoidable referentiality (1981: 5): the fact that some linguistic elements necessarily refer to something. This is a very broad criterion, which holds for many grammatical elements. Silverstein illustrates it with pronouns such as the $t u /$ vous opposition in French. Both $t u$ and vous clearly refer to the hearer.

2. Continuous segmentability (1981: 6): the fact that many linguistic expressions like 'the woman', 'walks' form a single segmentable unit, while others such as 'has ... -ed' do not. Silverstein assumes that speakers are potentially much more aware of single units in language than of discontinuous expressions. Silverstein does not present any psycholinguistic evidence for this, but this evidence may be found in studies on 'unit-like' processing in human memory. The notion of 'locality' in the generative tradition (e.g., Sportiche et al. 2014) may also be linked to this.

3. Relative presupposition (1981: 7): the fact that the use of a linguistic expression may require some specific set of pragmatic conditions. When we use 'this', we are either referring to something visually present in the domain of discourse, or to something mentioned before.

4. Decontextualized deducibility (1981: 10): the fact that the use of a particular form entails a particular presupposition, regardless of context. Thus, the use of 'my brother' entails that I have a brother.

5. Metapragmatic transparency (1981: 14): the fact that for many utterances the form of the utterance directly reveals the intention of the speaker. Thus 'can you open the window?' is more transparent in this sense than 'it is hot in here', even though both utterances may have been uttered with the same intention, namely conveying the need to open a window to the hearer. Speakers may be much more aware of dedicated grammatical patterns than of broad implicatures.

Altogether, Silverstein argues that these five criteria reflect the distinction that Whorf made between "cryptotypic" or deep semantics and "phenotypic" surface lexicalized forms (1981: 19), reflecting the distinction introduced by von Humboldt between 'inner' and 'outer' form. Clearly, Silverstein did not adduce experimental psycholinguistic evidence for the extent to which these five conditions contribute to the level of awareness that speakers may have of linguistic patterns or expressions, but this is possible in principle, and the conditions are plausible candidates as necessary, though not sufficient, conditions.

\subsection{Van Coetsem: Agentivity and the Stability Gradient}

The historical linguist Van Coetsem (1988) had a rather different take on the issue of levels of awareness and agency, but some of his conclusions coincide with those of Silverstein. He introduced 
the fundamental distinction between recipient-language agentivity (borrowing) and source-language agentivity (interference), which roughly corresponds to Thomason and Kaufman's (1988) distinction, which was couched in sociolinguistic terms, between maintenance-related and shift-related processes. The central idea in Van Coetsem's work is that in borrowing processes, the principles operating in the recipient language determine the eventual shape and structure of a borrowed item (like a word), while in interference the principles operating in the donor language determine this, as in the case of substrate influence, where patterns of the substrate language are transferred to the language to which the population of speakers has shifted. Notice that the notion of agency here is couched in terms of the languages involved, rather than the speakers of those languages, but it could be formulated in terms of speaker agency as well. To use the example of the Andes, when Quechua speakers adopt a word from Spanish (borrowing), the word is adapted to Quechua phonology and morphology, in Van Coetsem's (1988) model. In contrast, when Quechua speakers shift to Spanish, part of the phonetic and semantic distinctions made in Quechua will be imported into their version of Andean Spanish. In fact, the situation of source- and recipient-language agentivity is much more complicated in this situation, but this is beside the point here.

The distinction between the two types of agentivity naturally leads to a discussion of stability, as formulated in Van Coetsem's (1995) stability gradient, represented schematically in Table 1.

Table 1. Schematic representation of Van Coetsem's (1995) stability gradient.

\begin{tabular}{cc}
\hline More Stable & Less Stable \\
\hline Fewer constituents & More constituents \\
More structured & Less structured \\
Closed list & Open list \\
More automatic & Less automatic \\
Less conscious & More conscious \\
e.g., articulatory habits & e.g., content words \\
\hline
\end{tabular}

Stability is linked to consciousness or awareness. This is where Van Coetsem's work can be linked to Silverstein's criteria. As presented in Table 1, the most stable elements in Van Coetsem's model are structured single constituents from a closed list that are more or less automatic, and not subject to conscious manipulation. A typical example would be the use of the determiner 'the'. In contrast, the use of a string of several content words, as in 'laughs loudly' would be less stable. The first three stability criteria of Van Coetsem's list can be linked to some of Silverstein's criteria:

Continuous segmentability-Fewer constituents

Unavoidable referentiality-More structured

Relative presupposition-Closed list

This requires some tweaking since there is by no means an exact overlap between the expressions covered by these sets of criteria given that Silverstein departs from pragmatic and Van Coetsem from structural conditions.

\subsection{Sociolinguistic Work}

In variationist sociolinguistics the question of awareness has been discussed since the early work of William Labov. Labov (1972) distinguished three types of sociolinguistic variables in terms of their awareness level: stereotypes $<$ markers $<$ indicators (where indicators are the variables the speaker is least aware of, and stereotypes those that the speaker is most ware of). These three categories correlate with speaker style shifting as this is triggered by awareness of language forms: markers and stereotypes exhibit style shifting on the formal/informal continuum, but indicators do not, a sign that the speaker is in no way aware of the special status of the variable. Stereotypes differ from markers in that there is conscious awareness of them in the speech community. Markers signal sociolinguistic distinctions 
but operate below the radar, so to speak. In Labov (2007) the awareness distinctions are linked to linguistic change by the distinction between 'changes from below' (the level of awareness) which are not contact-induced and 'changes from above' (the level of awareness, but also higher levels of prestige) which do involve transfer between varieties. However, Labov's distinctions did not correspond directly to specific sets of categories or to components.

Therefore, Trudgill $(1981,1986)$ has tried to further operationalize distinctions regarding awareness in terms of the notion of salience. Building on the work of Weinreich (1953) and Weinreich et al. (1968), Trudgill has developed a model for dialect contact in which the notion of salience plays a central role. Salience is defined in terms of four parameters: stigmatization (the more stigmatized, the more salient), linguistic change (the more directly involved in change, the more salient), phonetic distance (the more distant from the other variety, the more salient), and phonological contrast (phonologically contrastive distinctions are more salient). Interestingly, as we discuss in Section 4.2, this notion of salience may also be involved in structural priming, which can in turn be related to language change.

In recent work, the traditional assumptions in the approach taken to variationist linguistics by Labov and Trudgill about the distinction between the vernacular below the level of consciousness and the more conscious adaptations to outside norms have been criticized. Campbell-Kibler (2010, 2016), studying the social perception of the pronunciation of the -ing ending as [In], argues that traditional variationist models which assume that complex social reasoning, referred to as the 'sociolinguistic monitor', is conscious and deliberate, in contrast with rapid and automatic linguistic behaviors often associated with the 'vernacular', is mistaken. Rather, data from the field of social cognition show that there is automatic processing in social perception, pursuing goals and stereotype-based priming (e.g., Dijksterhuis and Bargh 2001; Schütz-Bosbach and Prinz 2007; see also the papers in Babel 2016a). As we discuss later in Sections 4.1 and 4.2, this combination of both automatic and deliberate processes is also at play when it comes to priming of language use.

There has also been work in contact-induced language change that has shown that agency as a crucial factor in linguistic borrowing. Thus, in Babel (2016b) it is shown that speakers employ aspirates and ejectives, sounds from Quechua in their Bolivian Spanish 'to express affective stances such as anger, humor, and intimacy, and to index a local identity'. Babel's research suggests that the use of Quechua aspirates and ejectives in bilingual Spanish, which for Van Coetsem would be grouped under 'stable' and 'less conscious' articulatory habits can be transferred and are subject to conscious manipulation under specific circumstances. Admittedly, the use of these features does not violate Silverstein's 'continuous segmentability' directly, but their use in actual utterances requires attention to the larger phonotactic context (e.g., position within the word).

\section{Cross-Linguistic Priming and Language Change}

Using the distinctions made in the earlier literature by Von Humboldt, and subsequently Silverstein, Van Coetsem and the sociolinguistic work as a background, we now turn to priming, a mechanism that potentially drives language change (e.g., Garrod and Pickering 2013; Jäger and Rosenbach 2008; MacDonald 2013). Priming is the influence of recent experience with language on current processing of language. It takes place at multiple levels of language processing (e.g., semantic, structural, phonological, morphological, and orthographic), both within and across languages, in children and adults, and across different linguistic modalities (see Brysbaert et al. 1999; Frost et al. 2000; Jacob 2018; Lucas 2000; Pickering and Ferreira 2008; van Gompel and Arai 2018; van Hell and Tanner 2012; Van Heuven et al. 2001, for reviews and example studies). In the current paper, we focus specifically on structural priming. This is because, to our knowledge, most advances on the potential link between priming and language change have been made with respect to structural priming. This does not mean that we disregard other levels of linguistic processing-we will also discuss lexical influences on structural priming, for example, and we emphasize that it is important to examine the similarities and differences between structural priming and priming at other levels of processing in future research. See Section 4.4 for some suggestions for future research we make in this regard. We will now first 
present a selective review of structural priming and its functions (Section 3.1), after which we make the link with language change (Section 3.2).

\subsection{Structural Priming: Some Background}

Structural priming refers to the phenomenon that speakers tend to re-use syntactic structures they have heard or produced in recent discourse. This form of priming has been observed in various sentence structures, such as dative sentences, passives vs. actives, and relative clauses, and has been found based on both corpus and experimental methods, in several languages and, important for our discussion, between languages in bilingual speakers. Structural priming effects have been found both from production to production, from comprehension to production, from comprehension to comprehension, and with quite diverse tasks and techniques: picture description (e.g., Bock 1986), sentence completion (e.g., Corley and Scheepers 2002), dialogue tasks (e.g., Branigan et al. 2000), self-paced reading (e.g., Weber and Indefrey 2009), the visual world eye tracking paradigm (Arai et al. 2007), and neurocognitive measures like electroencephalography (EEG) (Tooley et al. 2009). For extensive reviews and recent insights on structural priming, see e.g., (Branigan and Pickering 2017; Dell and Ferreira 2016; Gries and Kootstra 2017; Hartsuiker and Pickering 2008; Mahowald et al. 2016; Pickering and Ferreira 2008; van Gompel and Arai 2018).

In most studies, structural priming has been used as an experimental technique to gain insight into the mental representations and levels of linguistic processing underlying language comprehension and production (e.g., Bock 1986; Branigan and Pickering 2017; Pickering and Branigan 1999). In such experiments, participants are presented with a sentence that is manipulated in terms of syntactic structure (i.e., the prime sentence), after which they must produce or comprehend a sentence themselves, often by having to describe a simple picture (i.e., the target sentence) or by listening to a target sentence. Structural priming takes place when participants' syntactic choices or comprehension processes in the target sentences are influenced by the syntactic structure of the prime sentence. These kinds of experiments are used to test theoretical models of the cognitive mechanisms and levels of processing of language use, based on the following logic: if information is primable, then this information represents a meaningful processing level. Using this logic, numerous studies have shown that 'syntax' is a meaningful level of processing in language use, yet is also connected to other levels of processing, such as the lexical level, phonological level, and semantic level (e.g., Bernolet et al. 2012; Bock 1986, 1989; Bock and Loebell 1990; Cleland and Pickering 2003; Pickering and Branigan 1999).

While monolingual priming experiments have been used to test monolingual processing models, cross-linguistic priming experiments have been used to test bilingual processing models. In cross-linguistic priming experiments, bilingual participants are presented with a prime sentence in one language after which they must produce (or in case of comprehension studies: comprehend) a sentence in another language. This technique provides a powerful window into the bilingual mind, especially with respect to the levels of processing at which cross-language activation can occur, which is a key issue in the psycholinguistics of bilingualism (cf. e.g., Hartsuiker and Pickering 2008; Kroll et al. 2006). That is, if bilinguals' syntactic choices are primed by the structure of a non-target-language, this can only be explained by assuming the existence of cross-language interaction at the syntactic level. This is indeed what has been found: cross-linguistic structural priming has been observed across many languages, using many tasks, both from the non-dominant to the dominant language and vice versa (e.g., Bernolet et al. 2007, 2012; Cai et al. 2011; Desmet and Declercq 2006; Hartsuiker et al. 2016; Hartsuiker et al. 2004; Jacob et al. 2017; Kantola and van Gompel 2011; Kidd et al. 2015; Kootstra and Doedens 2016; Loebell and Bock 2003; Salamoura and Williams 2006; Schoonbaert et al. 2007; Shin and Christianson 2009, 2012; Weber and Indefrey 2009). Based on this evidence, bilingual processing models have been developed which specify the mental representations of syntactic information in bilingual speakers, their links with other levels of processing (e.g., lexical, phonological), and the development of these representations, for example during second language learning (Hartsuiker and Bernolet 2017; Hartsuiker et al. 2004; Kootstra and Doedens 2016; Schoonbaert et al. 2007). 
Although the vast majority of evidence on priming is based on experimental manipulations, it is also evident from observational studies that priming is an inherent property of natural language use that takes place ubiquitously in real life, both in monolingual discourse (e.g., Bresnan et al. 2007; Weiner and Labov 1983), and in bilingual discourse (e.g., Fricke and Kootstra 2016; Travis et al. 2017; see Gries and Kootstra 2017, for a review). Indeed, Scherre and Naro (1991) even go so far as to claim that priming, or 'formal parallelism' as they call it, "should be considered a serious candidate for a universal of language use and processing" (p. 30). From this perspective, priming is a mechanism supporting communicative fluency: priming guides linguistic choices between conversation partners in social interaction, thus serving as a between-speaker transmission mechanism that encourages interactive alignment between dialogue partners (e.g., Pickering and Garrod 2004). Garrod and Anderson (1987), for example, had pairs of interlocutors play a 'maze game', where one of the interlocutors had to explain his/her location in a maze to another interlocutor. In negotiating their way around in these mazes, the interlocutors tended to coordinate the way in which they described elements of the maze, arguably to ensure that they are both referring to the same element of the maze, and thus to increase the likelihood of communicative success. Likewise, using a picture-description task,

mboxciteauthorB14-languages-421416 (2000) found that participants tended to use the same syntactic structure as their dialogue partner when describing pictures of transitive events to each other. Priming between interlocutors is regarded as the mechanism underlying this linguistic coordination (Pickering and Garrod 2004). The underlying idea of this priming is that interlocutors' situations models are aligned: by using the same language and structures for referring to the same things, they increase the likelihood that their mental images of what they are talking about (i.e., their situation models) are the same as well. Thus, priming in dialogue aids successful communication, which in turn can be linked to other dimensions of research on linguistic adaptation in conversational settings, such as speech accommodation (Giles et al. 1991), audience design (Brennan and Clark 1996), and Grice's (1975) cooperative principle. We return to these perspectives in Section 4.

Importantly, in addition to a communicative function, priming appears to have a learning function. That is, priming effects have been reported to be cumulative, or to hold over long stretches between the prime and the target, sometimes even over multiple days (e.g., Bock and Griffin 2000; Hartsuiker et al. 2008; Kaschak 2007; Kaschak et al. 2011; Kaschak et al. 2012; Shin and Christianson 2012). Based on among other things these long-term and cumulative priming effects, priming is hypothesized to serve as a mechanism of implicit language learning (e.g., Chang et al. 2006; Dell and Chang 2014; Jaeger and Snider 2007, 2013). It can therefore be argued that priming is not merely a methodological technique but is in fact a fundamental mechanism of language use with important socio-pragmatic and learning functions. This combination of socio-pragmatic and learning functions is exactly what makes structural priming a plausible potential mechanism of language change.

\subsection{Priming and Language Change}

Based on the observations that priming (1) takes place in real life and (2) appears to underlie implicit learning of syntax, it is not farfetched to assume a link between priming and language change. The hypothesized mechanism is as follows: given that structural priming is a key mechanism of communicative exchange that influences people's linguistic choices and given that this form of priming can have long-term, cumulative effects (learning), structural priming between members of a linguistic community can in the long run influence the frequency distributions with which linguistic structures are used. Based on this argumentation, structural priming has indeed been proposed as a potential mechanism of language change (e.g., Garrod and Pickering 2013; Jäger and Rosenbach 2008; Loebell and Bock 2003; MacDonald 2013). For example, Jäger and Rosenbach (2008, p. 85) state that 'priming is the "missing link" in evolutionary models of language change in that it provides for a plausible linguistic replicating mechanism, i.e., an "amplifier" of linguistic units'. Likewise, Garrod and Pickering (2013) point out that the tendency of interlocutors to copy elements of each other's language use in dialogue (i.e., interactive alignment), which is based on linguistic priming between interlocutors, 
can lead to routinization of linguistic expressions within speech communities as a long-term effect ${ }^{1}$. This routinization is based on repeated activation of linguistic representations in dialogues. Such a view on priming as a form of continuous adaptation to the ongoing linguistic environment can also be related to usage-based and evolutionary theories on language acquisition and change (e.g., Bybee 2010; Croft 2000; Tomasello 2003) and to theories that emphasize the dynamic nature of language processing in relation to continuous time (e.g., Beckner et al. 2009; de Bot et al. 2007).

Because structural priming also occurs between languages, the idea of structural priming as a mechanism of language change can of course also take place between languages, potentially leading to contact-induced language change (cf., Fernández et al. 2017; Loebell and Bock 2003; Kootstra and Doedens 2016; Kootstra and Muysken 2017; Kootstra and Şahin 2018; Travis et al. 2017). Contact-induced language change can be defined here as (probabilistic) differences in linguistic preferences between speakers that have been frequently using another language as well, compared to speakers that have not (e.g., Doğruöz and Backus 2009; Indefrey et al. 2017; Moro and Klamer 2015; Otheguy et al. 2007; Villerius 2019). Indeed, consistent with the hypothesized link between contact-induced change and cross-linguistic priming, Fernández et al. (2017) observed that Spanish-English bilinguals were more tolerant than monolinguals in their judgments of L1 language structures that contained innovations from their L2, and that these results could be linked to other results in this population of bilinguals, in which they observed priming of innovative language use across languages. Related results were found by Travis et al. (2017; see also Torres Cacoullos and Travis 2010), who studied the production of first-person subject pronouns in a bilingual corpus of Spanish-English bilinguals from New Mexico, which are always produced in English but can either be dropped or overtly produced in Spanish. They found that the use of overt first-person subject use in Spanish was among other things influenced by whether it has been overtly used in a previous sentence, even when this previous sentence was English. In other words, these speakers were primed both within and across languages in their use of the overt first-person subject. Given that the first-person subject is always overtly produced in English, this priming across language may well cause these bilinguals to produce overt subjects relatively often in Spanish, potentially leading to a shift in the frequency distributions over overt vs. dropped subject use in this linguistic community. Similar results have recently been found by Sodac1 et al. (2019) in Turkish-Dutch bilinguals. Dutch is like English in that subject pronouns are always overtly produced, while Turkish is like Spanish in that overt use of subject pronouns is not standard and follows certain pragmatic regularities. As a result, speakers of Turkish in the Netherlands have been reported to show unconventional variation in subject pronoun use (Doğruöz and Backus 2009), which is evidence of contact-induced change. Sodac1 et al. investigated the potential role of structural priming in this process. They asked Turkish-Dutch bilinguals to listen to short stories in Dutch or Turkish and respond in Turkish to subsequently presented Turkish prime sentences, which contained either an overt or a null subject pronoun. The participants tended to use overt subjects when being primed with an overt subject, and interestingly, this priming effect was stronger in the conditions where the short story was presented in Dutch (i.e., a bilingual setting). Thus, priming of subject realization was boosted by a language contact setting, which makes the link between priming mechanisms in bilinguals and mechanisms of cross-language activation in language contact settings even more plausible.

Another study that has recently investigated the link between cross-language structural priming and contact-induced language change is Kootstra and Şahin (2018). Kootstra and Şahin studied the production of dative sentences in Papiamento (a creole language spoken in the Netherlands Antilles) by Papiamento-Dutch bilinguals. While Dutch dative sentences can be produced relatively flexibly in two different ways (i.e., PO-structure, like de jongen geeft de bal aan het meisje [the boy gives the

1 Note that this routinization as a result of priming can just as well be seen as the opposite of change: speakers copy each other, leading to entrenchment of a specific linguistic preference (we thank a reviewer for pointing us to this). But when this routinization within a speech community leads to differences in linguistic preferences compared to another or the 'standard' speech community, then it is plausible to maintain that priming of linguistic choices can indeed lead to change. 
ball to the girl] and DO-structure, like de jongen geeft het meisje de bal [the boy gives the girl the ball]), Papiamento dative sentences tend to be produced exclusively with a DO-structure (Bruyn et al. 1999). Consistent with these different structural preferences between Dutch and Papiamento, Kootstra and Şahin found that Papiamento speakers in the Netherlands use the DO-structure less than Papiamento speakers in Aruba. Given that the speakers in the Netherlands were exposed to and used Dutch more than the speakers in Aruba, this difference in syntactic choices could well be influenced by the less-absolute Dutch syntactic preferences. In other words, this difference between Aruba-Papiamento and Netherlands-Papiamento could be a result of contact-induced language change. If Dutch syntactic preferences are indeed a factor in this difference between different speakers of Papiamento, then it should be the case the structural priming of dative sentences from Dutch to Papiamento is possible. Put differently, if cross-language structural priming of the dative alternation does not occur from Dutch to Papiamento, then it is difficult to maintain that the difference between Aruba-Papiamento and Netherlands-Papiamento is because speakers of Netherlands-Papiamento have taken over elements of how the dative is produced in Dutch. Kootstra and Şahin tested this hypothesis in a cross-language structural priming experiment, and indeed found evidence of structural priming from Dutch to Papiamento: the tendency to produce a DO structure in Papiamento was higher when the participants had just heard a Dutch DO sentence, and vice versa for PO sentences.

Thus, multiple recent studies have provided indications that cross-language structural priming is a plausible mechanism driving contact-induced language change. Given that awareness and human agency are seen as important factors of language change by some historical linguists (see Section 2), an interesting next step in elucidating the relation between priming and language change is to explore the extent to which awareness and agency are involved in priming.

\section{Priming in Relation to Awareness and Agency}

Now that we have discussed cross-language structural priming and its potential relation to contact-induced language change, we explore the relation between priming and forms of linguistic awareness and agency. We hope to make clear that although priming is typically associated with processes below the level of awareness, it is also modulated by factors related to conscious awareness and deliberate action.

\subsection{Priming as an Automatic Process}

Priming is generally assumed to be an automatic, below the radar process (Pickering and Garrod 2004), based among other things on research in social cognition assuming a direct link between perception, action, and mental states (e.g., Dijksterhuis and Bargh 2001; Schütz-Bosbach and Prinz 2007). This assumption of automatic priming also makes it possible to explain why language production, which is assumed to be a complex, staged process from conceptualization to articulation (e.g., Levelt 1989), is nevertheless mostly quite fluent. That is, instead of having to start each utterance from scratch and plan it from conceptualization to articulation, priming leads to pre-activation of linguistic representations, which makes it possible to make shortcuts in the production planning process, and thus facilitates fluency of language production (Ferreira and Bock 2006; Garrod and Pickering 2004). The automatic nature of priming is also reflected in the fact that priming entails implicit language learning. As Bock and Griffin (2000) note, this learning is independent of conscious intentions to re-use the structure of a sentence with new words, takes place even when speakers do not try to remember the prime sentence, and does not necessitate explicit attention to the form of a prime sentence. The power of implicit priming processes is corroborated in a study by Shin and Christianson (2012), who studied short-term and long-term structural priming in L2 learners, focusing particularly on the potential role 
of explicit instruction. The data yielded structural priming effects, even a day after testing ${ }^{2}$. Effects of explicit instruction were also significant and indeed strengthened accuracy on top of the priming effects, but this was only the case in the short term, not in the long term; only the implicit process of priming led to persisting learning effects. Perhaps the strongest indication of automaticity in priming comes from a study by Ferreira et al. (2008), who examined structural priming and recognition memory of sentences in amnesic speakers (whose declarative memory is impaired) compared to a control group. They asked these people to reproduce prime sentences, to then describe pictures that could be described with the primed structures, and finally to state whether they recognize the prime sentence that was previously presented to them. Interestingly, both the amnesic speakers' and the control group's picture descriptions were primed by the prime sentences, but the amnesic speakers had no recognition memory of the prime sentences presented to them, whereas the control group had. This finding is an important indication that structural priming is based on procedural rather than declarative memory and does not require conscious memory of the primed structures. Thus, priming clearly involves automatic processes. But does that mean that awareness and/or deliberate processes are not at all involved? And to what extent are there differences in awareness across different levels of linguistic processing, thus linking up the priming literature with the previously discussed linguistic literature? As we discuss below, both linguistic and socio-pragmatic dimensions are involved.

\subsection{Priming and Linguistic Levels of Awareness}

Given the automaticity and implicit nature of priming, is there indeed a role to play for awareness in priming? We believe there is, in the sense that the strength and nature of automatic priming may be influenced by explicit memory factors and strategic discourse processes.

These explicit memory factors are related to the linguistic perspective introduced in the first sections of this manuscript, where we focused on differential levels of awareness in relation to different language components. In the priming literature, this difference between linguistic levels of processing is reflected in the so-called lexical boost effect of structural priming. The lexical boost effect refers to the oft observed finding that structural priming effects are enhanced (i.e., boosted) in the case of lexical overlap between the prime and the target (e.g., Cleland and Pickering 2003; Mahowald et al. 2016; Scheepers et al. 2017). Interestingly, whereas the structural priming effect itself appears to be stable and long-lasting and can thus be linked to processes of implicit learning and language change, the lexical boost effect is relatively short-lived and fleeting, which makes it unlikely to be driven by implicit memory processes. Rather, it is assumed that the lexical boost effect is based on explicit memory of the prime sentence (e.g., Chang et al. 2006; Scheepers et al. 2017); it can be argued that explicit memory of the prime sentence makes the lexical similarity between the prime and the target sentence relatively salient, to the extent that it leads to stronger priming.

Thus, lexical influences on structural priming are guided by explicit memory processes, whereas structural priming itself is driven by implicit memory processes. This is neatly consistent with Van Coetsem's (1995) stability gradient, in which structured, closed class elements (e.g., priming of syntactic structure) are less consciously processed and therefore more stable, whereas open class elements like content words (e.g., the words used in priming studies, leading to lexical boost effects) are more consciously processed and hence less stable ${ }^{3}$. A somewhat puzzling finding here is that the lexical-boost effect, which is supposedly served by explicit memory, is short-lived. How can this

2 From the perspective of a historical linguist, a day after testing may not be seen as 'long term'. However, what this effect shows is that priming effects do not disappear directly; they linger and can thus influence linguistic choices beyond the next trial, and even beyond testing sessions. Given that priming takes place frequently in real life, the 'long-term' potential of priming effects can lead to cumulative priming of linguistic choices.

3 This does not mean that lexical priming does not involve automatic processing. Indeed, many studies on lexical priming have found that these forms of priming even occur in the absence of conscious processing of the prime (see e.g., Forster 1998). Importantly, however, in the specific context of structural priming, it is plausible to assume that explicit memory of lexical overlap between prime and target underlies the boosted structural priming effect. 
short-lived effect be linked to the role of awareness in language change, which is of course a long-term process? One way in which this can be envisaged is that even though the lexical effects are brief, these short-term processes do strengthen structural priming effects, which are more enduring and can thus be linked to language change. It should also be mentioned that we refer here to an effect of lexical priming on structural priming, not on lexical priming itself. Indeed, evidence of lexical entrainment, in which interlocutors adapt their lexical choices to each other over the course of a conversation (e.g., Brennan and Clark 1996), is an example of how lexical priming in the absence of structural priming can also have long-term effects. We return to the issue of priming at different levels of processing in Section 4.4.

Another way in which linguistic elements can be related to processes of awareness in structural priming is in the finding that priming turns out to be relatively strong when the prime is unusual, infrequent or surprising (e.g., Bernolet and Hartsuiker 2010; Jaeger and Snider 2007, 2013; this effect is related to the inverse frequency effect in priming). Although these effects of course involve unconscious and automatic aspects of processing (i.e., language users do not consciously keep track of the frequency of words or linguistic structures), it can be argued that the likelihood of consciously processing linguistic structures will be higher when these structures are infrequent/surprising than in the case of highly frequent, ordinary structures. That is, it can be assumed that the surprising prime, which constitutes a mismatch between an expected and an observed linguistic element, requires increased attention to the observed language and perhaps even reprocessing (as has also been found in the monitoring literature, cf., e.g., van de Meerendonk et al. 2009). Indeed, the psycholinguistic notion of 'surprisal' of linguistic stimuli has recently been linked by Jaeger and Weatherholtz (2016) to the sociolinguistic notion of 'salience', which is in turn relatable to the notion of awareness in the sense that salient linguistic elements lead to higher levels of awareness. As Jaeger and Weatherholtz put it, "variants that are unexpected given the listener's prior expectations about linguistic variables (including, broadly speaking, the listener's language background) should be more salient in the moment they are experienced" (p. 2). The fact that this subsequently results in relatively strong priming effects can be explained as a form of error-based learning in which prediction and adaptation to the environment plays a role, as already touched upon earlier in this paper and discussed in the work of Franklin Chang, Gary Dell, and Florian Jaeger, among others (e.g., Chang et al. 2006; Dell and Chang 2014; Jaeger and Snider 2007, 2013). What is more, this form of error-based, implicit learning based on input that 'catches the eye' may also be at the core of the noticing hypothesis in the area of second language acquisition (e.g., Schmidt 1990). As also emphasized by Ellis (2015), such conscious processing of salient information (leading to noticing) is a way in which explicit memory processes can support the emergent and exemplar-based process of implicit language learning. Most importantly for our discussion, however, is that the notion of salience is also likely to be involved in language change: linguistic elements tend to be more directly involved in linguistic change when they are more salient (Trudgill 1986, see also Section 2.4). As such, there appears to be an interesting link between priming, salience, and language change ${ }^{4}$.

In the context of surprisal effects, it is interesting to briefly discuss one more finding from the study by Kootstra and Şahin (2018). Kootstra and Şahin found that Papiamento speakers in Aruba, who had a strong preference for the DO structure, turned out to produce a relatively high number of PO structures when the movie clip description task was embedded in a priming paradigm, compared to speakers in the Netherlands. They interpreted this as a surprisal effect: given that these speakers in principle have a strong preference for the DO structure, the (Dutch) PO sentences the participants were primed with represent infrequently experienced structures that may have been surprising for them, leading to a relatively high number of PO movie clip descriptions. Surprisal effects may thus

4 Note that the notion of salience is, in itself, a complex notion that is defined in multiple ways, based on many different criteria, sometimes with a risk of circularity (MacLeod 2015). Future research may lead to more clarity of what salience exactly is, and how it is related to different aspects of linguistic behavior and change. 
also take place in situations where structural priming is studied in connection with language change processes. Obviously, however, given that priming is at least partially automatic, more research is needed to establish the extent to which surprisal effects are indeed related to conscious processing, for example by correlating measures of metalinguistic awareness with surprisal effects in structural priming, or by measuring brain activity or pupil dilation when processing such sentences-some ERP components (event-related brain potentials in EEG studies) have actually been associated with awareness and expectation-based processing (e.g., Düzel et al. 1997; Melloni et al. 2011). See Section 4.4. for suggestions as to how such measures could be applied with respect to cross-language structural priming and contact-induced language change.

In sum, both the lexical boost effect and the surprisal effect on structural priming point to a potential relation between priming and awareness. This suggests that awareness of linguistic elements is not only determined by discrete aspects of the linguistic elements involved, like the difference in stability between content words (lexical level of processing) and syntactic structure (syntactic level of processing), but also by distributed aspects, such as the surprisal of the linguistic elements involved, which is typically guided by factors such as (subjective) frequency and language user's linguistic experiences. This then implies that the stability gradient as proposed by Van Coetsem (1995), which is based on discrete, grammatical notions like the number of constituents, the amount of structure involved, and whether closed-list or open-list elements are involved, should perhaps be extended with distributed notions in order to provide a more complete account of what stability of language elements entails. The stability gradient could for example be extended with a dimension called 'surprisal', where elements or structures with a high surprisal value (i.e., unlikely and often infrequent elements) are more consciously processed and therefore expected to be less stable than elements or structures with a low surprisal value.

\subsection{Priming and Socio-Pragmatic Dimensions of Awareness and Agency}

In addition to different linguistic elements invoking different level of awareness, it should be emphasized that there are also socio-pragmatic factors that can influence the degree of awareness and agency in language processing. With respect to the priming literature, this is reflected in the difference between 'automatic' priming and 'strategic' priming. Strategic priming is supposed to be based on beliefs about one's interlocutor, agreements between interlocutors, and feedback from interlocutors (Garrod and Pickering 2007) and can be argued to be more likely under conscious control of the speaker than automatic priming. For example, Brennan and colleagues (e.g., Brennan and Clark 1996; see also Brennan and Hanna 2009) found that dialogue partners jointly construct ways of referring to specific concepts, and that this way of referring is partner-specific (i.e., audience design). Likewise, Branigan et al. (2010) observed that beliefs about the interlocutor influence priming effects, in the sense that priming effects between a human and a computer were different from priming effects between two humans. The fact that these beliefs about the interlocutor determine the strength and nature of the priming effect is an indication of how goal-directed socio-pragmatic considerations can influence the automatic process of priming. Although this goal-directed form of priming is likely to still involve automatic processes, it is also clear that differential adaptation of language use as a function of beliefs about the interlocutor necessitates intentional thoughts that require a certain level of awareness and human agency.

A similar form of intentional adaptation to one's interlocutor is reflected in the phenomenon of communication accommodation (e.g., Giles et al. 1991), which has its foundations in social psychology. Communication adaptation assumes that people accommodate their speech styles to each other based on their perceptions of the social environment and to gain a specific goal, such as communicative efficiency, social approval, or the specification of one's social identity ${ }^{5}$. One form of communication accommodation is 'convergence', which refers to the phenomenon where a speaker adapts his/her

5 This form of accommodation is clearly also related to the notion of foreigner talk (e.g., Ferguson 1975; Tarone 1980). 
speech in interaction to the extent that it closely resembles the speech of his/her dialogue partner. The social benefits of such goal-directed linguistic accommodation have for example been observed by van Baaren et al. (2003), who report that when a server repeats a customer's order, this leads to increased tips given to this server.

It can be argued that accommodation, in which a speaker adopts elements of the speech of the dialogue partner, is related to forms of priming in conversation, such as interactive alignment in dialogue (Pickering and Garrod 2004), which is also based on the copying of linguistic elements of the interlocutor's language use. Whereas priming emphasizes the automatic, cognitive aspects of interactive alignment, accommodation theory emphasizes the social, goal-directed aspects of it (cf., Trofimovich and Kennedy 2014). Communication accommodation can also be related to sociolinguistic variation research on variable speech production as acts of identity (Eckert 2012; Mendoza-Denton 2002). Of course, even here, automatic forces will play a role, but the fact that language users can choose to either converge or diverge with their interlocutor to obtain a specific social effect indicates that human agency and deliberate action play an important role in these forms of linguistic accommodation. As such, the theory of communication accommodation is also related to theories of meaning and action in which linguistic behavior is regarded as intentional and strategic (e.g., Grice 1975; Searle 1969; cf., Mendoza-Denton 2002). It is interesting to observe how these intentional aspects of language use are intricately intertwined with automatic, unconscious aspects, such as priming. It is also interesting to keep in mind that, as among others argued by Thomason (2006), agency presupposes awareness, and that agency in linguistic behavior facilitates intentional language change.

\subsection{Some Suggestions for Future Research on Priming and Awareness in Relation to Language Change}

It is evident from the previous section that priming is an automatic and unconscious process, yet that the strength and nature of this process can be influenced by linguistic dimensions and socio-pragmatic factors that invoke human agency and a certain level of awareness or conscious processing. This, in a way, can be related to the interface between implicit and explicit memory as it has been proposed in cognitive psychology (e.g., Jacoby 1991) and for example in the field of second language acquisition, where explicit learning of form-meaning associations in a new language has been found to ameliorate and accelerate the input-driven process of implicit language learning (e.g., Ellis 2015).

To arrive at a more detailed and comprehensive view of priming, levels of awareness, and agency in contact-induced language change, various complementary strategies would need to be combined, such as:

1. A grammatical analysis leading to more specific hypotheses about possible awareness of linguistic items and structures, building on the work of Van Humboldt and then Silverstein and Van Coetsem, but more systematically exploring different types of items one by one. As already alluded to in Section 4.2, such a linguistic analysis should not only incorporate discrete aspects of language, but also distributional aspects based on frequency of occurrence, such as surprisal.

2. Experimental work testing the awareness of speakers of these items and structures and linking it to psycholinguistic theories on the cognitive mechanisms of language production and comprehension. In the current paper, we explored the potential links between research on structural priming, language change, and awareness of linguistic structures. Naturally, the next step is the further test these potential links, using fine-grained measurements that allow for a sound assessment of conscious awareness in linguistic processing, and how this relates to priming. Of course, this experimental work can also inform the linguistic analyses we suggest in point 1 above. In fact, Branigan and Pickering (2017) have recently proposed that priming research could indeed serve as a key experimental approach to inform theories of linguistic structure.

3. Parallel to this experimental work, a detailed meta-analysis of the priming literature about the linguistic items and patterns involved and how it relates to strategic and automatic aspects of 
priming. Such a meta-analysis could not only inform the experimental work suggested in point 2 above, but also the linguistic analysis suggested in point 1 .

4. Further development and testing of how cross-linguistic priming and awareness of linguistic structures are related to contact-induced language change. After all, the empirical basis of the link between structural priming and contact-induced change is still rather limited, especially in relation to awareness of linguistic structures-the only evidence pointing in this direction are surprisal effects found by Kootstra and Şahin (2018). Therefore, more research on cross-linguistic priming and contact-induced change should be done, exploring multiple language pairs and multiple linguistic items and structures, preferably varying in terms of their predicted level of conscious processing (based on research suggested in points 1 and 2 above).

As an example of the kind of experimental work that could be done, we now formulate some concrete suggestions for future research. These research suggestions can be done across languages in a language-contact setting (thus potentially informing strategy 4) but can in some cases also simply be done in one language only with monolinguals, depending on the specific research question (cf., strategy 2). We hope that these suggestions will inspire new ways in which linguistic, sociolinguistic, and psycholinguistic theories and methods can be combined.

One important suggestion is to investigate the extent to which long-term effects of priming also apply in other domains than the syntactic domain. To what extent are processes such as lexical and phonetic convergence across speakers (e.g., Brennan and Clark 1996; Pardo 2006) based on the same mechanisms underlying structural priming, for example, and to what extent does convergence on one linguistic level modulate convergence at another? One hypothesis that can be formulated on this concerns the potential role of the lexical boost effect in relation to long-term priming effects. Although previous research has shown that the lexical boost effect is typically short-term in nature, it may be interesting to investigate what happens when the role of lexical overlap is exaggerated, for example by creating an experimental situation in which lexical overlap between prime and target sentences is sustained. Manipulations such as these may well lead to a situation in which specific lexical items (e.g., verbs) are associated with specific structures, which is in an important characteristic of natural language (i.e., verb bias; cf., Bernolet and Hartsuiker 2010; Ferreira 1996; Gries and Stefanowitsch 2004; Jaeger and Snider 2013; Kootstra and Doedens 2016). In fact, research by Coyle and Kaschak (2008) suggests that patterns of experience with verbs indeed affect long-term cumulative structural priming. As a next step, it would be interesting to investigate this in a language contact situation, to explore how the interface between lexical and structural aspects of priming influence long-term priming between languages ${ }^{6}$. For example, bilingual participants could be biased with specific verb-structure combinations of dative sentences in one language by presenting them with a range of sentences in which specific verbs always go with specific structures (e.g., the verb 'give' always goes with a prepositional object structure like x-give-y-to-z, whereas the verb 'hand' always goes with a double object structure like $x$-hand-z-y). In a subsequent priming phase, participants could then be presented with sentences fragments in the other language that contain the translation equivalent of these verbs, which they then have to complete. If patterns of experience with verbs in one language prime syntactic choices in the other language, then this is additional evidence of how exposure to one language from a previous experimental phase can change linguistic preferences in the other language in a new experimental phase. Follow-up experiments could then examine to what extent priming effects change when prime sentences are presented in which the verb is combined with the opposite structure as in the bias, thus manipulating the surprisal values of these items. This should then lead to relatively strong priming effects. In addition, follow-up experiments could analyze the longevity of the priming effect as induced by the bias phase. Such long-term priming investigations can further inform the potential of

6 See Brown (2015) for interesting data on how cumulative effects of patterns of experience may influence phonological aspects of speech production in language-contact setting. 
priming as a mechanism supporting diachronic language change, based on the arguments put forward by for example Jäger and Rosenbach (2008).

Another hypothesis that could be tested concerns the role of surprisal. Jaeger and Weatherholtz (2016) explain that surprisal of linguistic elements is intimately connected with specific social contexts, in the sense that unexpected words or structures are indicative of specific 'sociolinguistic lects'. Thus, 'surprising' linguistic elements can be seen as sociolinguistic identity markers, showing how language change can be based on routinization of linguistic expressions between members of the same linguistic community (Garrod and Pickering 2013). In this way, elements that are surprising in one linguistic community may not be surprising in other linguistic communities. If this is the case, then it should be the case that the surprisal effect of priming is dependent on the speakers' personal language experiences, and particularly on the speakers' and hearers' experience with the specific sociolect in which this 'surprising' language use takes place. This could for example be done by designing an experiment in which speakers from different linguistic communities are primed with words or syntactic structures that are specific to only one of these communities. If surprisal influences priming, then priming effects should be strongest when participants are primed with words or syntactic structures from the other linguistic community.

To gain more insight into the extent to which surprisal and specific levels of linguistic processing are indeed relatable to levels of awareness, more research is needed in which aspects of awareness are explicitly measured and related to aspects of priming and linguistic processing. This can for example be done by collecting measures of (meta)linguistic awareness and relate these measures to aspects of linguistic processing and linguistic behavior, and of course specifically to forms of structural priming. Interestingly, innovations in the measurement of human consciousness has made it possible to measure aspects of conscious awareness without having to ask participants for introspection (cf., Düzel et al. 1997; Kang and Wheatley 2015; Melloni et al. 2011). For example, electrophysiological data can be collected of how language users process structures or constructions with a high surprisal value compared to those with a low surprisal value. If 'surprising' structures are indeed processed more consciously, then this may be reflected in ERP components known to capture awareness (e.g., Düzel et al. 1997; Melloni et al. 2011). Interestingly, in addition to ERP components, pupil dilation has been found to be linked to conscious awareness (e.g., Kang and Wheatley 2015). It is for example possible to measure people's pupil dilation while they listen to or read sentences or constructions of which the surprisal value is manipulated. Such comprehension measurements can subsequently be combined with a production task, e.g., in the form of a priming task in which participants first process a sentence (with surprisal values manipulated) and then have to describe a picture that can be described using a similar structure as the prime sentence or not. In addition to structures that vary in terms of surprisal, similar studies could be done with linguistic elements that vary on other linguistic aspects, for example on aspects from Van Coetsem's (1995) stability gradient. Importantly, in addition to elucidating the relation between awareness and surprisal and how this relates to priming, this kind of research also makes it possible to further explore how implicit vs. explicit aspects of language comprehension (e.g., by comparing EEG or eye-tracking data with acceptability judgment data) influence processing or production of (a) subsequent sentence(s), and may thus also provide more insight into the link between language comprehension and language production (e.g., MacDonald 2013). This kind of research may not only be interesting from a cognitive processing perspective on language but may also inform linguistic theories on levels of language use and their interrelations.

In addition to these hypotheses in relation to the linguistic elements involved, priming appears to be influenced by the speakers' beliefs, attitudes and expectations (i.e., in the form of strategic priming). In relation to language change, one such belief concerns the speakers' personal norms and values about the language they use. It can for example be argued that priming across languages is probably weaker in speakers who strongly value the prescriptive grammatical rules of the language they speak than in speakers who are more relaxed on this matter, especially when the priming involves innovative structures or code-switching, for example. By investigating situations such as these, it is possible to 
gain more insight into how automatic forces on linguistic behavior (priming) combine with human agency and intentional aspects of language use.

\section{Conclusions}

In this paper we have combined two approaches to the question of awareness and language change: the linguistic approaches of Silverstein and Van Coetsem, ultimately inspired by Wilhelm von Humboldt's work, and psycholinguistic approaches involving priming, inspired by work of researchers such as Bock and Pickering.

In the linguistic literature, attempts are made to establish classifications or hierarchies regarding linguistic features or components that may be involved in conscious linguistic change, 'above the level of awareness'. In the psycholinguistic literature attempts are made to characterize the processes underlying the use of these linguistic features or components; the literature shows that there are various views about the 'automatic' or 'strategic' nature of priming, and that awareness of linguistic elements is likely to be not only based on discrete linguistic features or components, but also on more distributed and context-specific variables, such as subjective frequency and language users' personal linguistic experiences (within linguistic communities). The two perspectives complement one another, and a concise review of the priming literature suggests that some of the linguistic variables involved in priming studies are indeed driven by explicit processes that likely involve more conscious processing. In addition, we showed that socio-pragmatic variables may also influence the level of awareness when it comes to priming of linguistic behavior, and we formulated a number of hypotheses of how these factors related to awareness in priming can be linked to processes of language change.

In this paper, we made a first step in exploring the relation between contact-induced language change, cross-linguistic priming, and levels of linguistic awareness and human agency. Importantly, we indicated that implicit forces on linguistic behavior (e.g., priming/implicit language learning) can be modulated by conscious explicit memory processes (e.g., lexical choice, speakers' beliefs, etc.). In this way, our view on the interface between unconscious and conscious processes in language change are consistent with views from psychology and second language acquisition on implicit and explicit memory processes. Only by combining insights from different fields and further empirical investigation can we arrive at a more principled understanding of this complex area of research.

Author Contributions: Conceptualization: P.M. and G.J.K.; writing—original draft preparation: P.M. and G.J.K.; writing-review and editing: P.M. and G.J.K.; project administration, P.M.; funding acquisition, P.M.

Funding: This research was funded by an Advanced Grant from the European Research Council, ERC-2008-AdG, SH5; 'Traces of Contact: Language contact studies and historical linguistics', awarded to Pieter Muysken.

Conflicts of Interest: The authors declare no conflict of interest. The funding sponsors had no role in the design of the study; in the collection, analyses, or interpretation of data; in the writing of the manuscript, or in the decision to publish the results.

\section{References}

Arai, Manabu, Roger P. G. van Gompel, and Christoph Scheepers. 2007. Priming ditransitive structures in comprehension. Cognitive Psychology 54: 218-50. [CrossRef] [PubMed]

Babel, Anna M., ed. 2016a. Awareness and Control in Sociolinguistic Research. Cambridge: Cambridge University Press. [CrossRef]

Babel, Anna M. 2016b. Affective motivations for borrowing: Performing local identity through loan phonology. Language and Communication 49: 70-83. [CrossRef]

Beckner, Clay, Richard Blythe, Joan Bybee, Morten H. Christiansen, William Croft, Nick C. Ellis, John Holland, Jinyun Ke, Diane Larsen-Freeman, and Tom Schoenemann. 2009. Language is a complex adaptive system: Position paper. Language Learning 59: 1-26. [CrossRef]

Bernolet, Sarah, and Robert J. Hartsuiker. 2010. Does verb bias modulate syntactic priming? Cognition 114: 455-61. [CrossRef] [PubMed] 
Bernolet, Sarah, Robert J. Hartsuiker, and Martin Pickering. 2007. Shared syntactic representations in bilinguals: Evidence for the role of word-order repetition. Journal of Experimental Psychology: Learning, Memory, and Cognition 33: 931-49. [CrossRef] [PubMed]

Bernolet, Sarah, Robert J. Hartsuiker, and Martin J. Pickering. 2012. Effects of phonological feedback on the selection of syntax: Evidence from between-language syntactic priming. Bilingualism: Language and Cognition 15: 503-16. [CrossRef]

Birdsong, David. 1989. Metalinguistic Performance and Interlinguistic Competence. Berlin and New York: Springer. [CrossRef]

Bock, J. Kathryn. 1986. Syntactic persistence in language production. Cognitive Psychology 18: 355-87. [CrossRef]

Bock, J. Kathryn. 1989. Closed-class immanence in sentence production. Cognition 31: 163-86. [CrossRef]

Bock, J. Kathryn, and Zenzi M. Griffin. 2000. The persistence of structural priming: Transient activation or implicit learning? Journal of Experimental Psychology: General 129: 177-92. [CrossRef]

Bock, J. Kathryn, and Helga Loebell. 1990. Framing sentences. Cognition 35: 1-39. [CrossRef]

Branigan, Holly P., and Martin J. Pickering. 2017. An experimental approach to linguistic representation. Behavioral and Brain Sciences 40: e282. [CrossRef] [PubMed]

Branigan, Holly P., Martin J. Pickering, and Alexandra A. Cleland. 2000. Syntactic co-ordination in dialogue. Cognition 75: B13-B25. [CrossRef]

Branigan, Holly P., Martin J. Pickering, Jamie Pearson, and Janet F. McLean. 2010. Linguistic alignment between people and computers. Journal of Pragmatics 42: 2355-68. [CrossRef]

Brennan, Susan E., and Herbert H. Clark. 1996. Conceptual pacts and lexical choice in conversation. Journal of Experimental Psychology: Learning, Memory, and Cognition 22: 1482-93. [CrossRef] [PubMed]

Brennan, Susan E., and Joy E. Hanna. 2009. Partner-specific adaptation in dialog. Topics in Cognitive Science 1: $274-91$. [CrossRef]

Bresnan, Joan, Anna Cueni, Tatiana Nikitina, and R. Harald Baayen. 2007. Predicting the dative alternation. In Cognitive Foundations of Interpretation. Amsterdam: KNAW, pp. 69-94.

Brown, Esther L. 2015. The role of discourse context frequency in phonological variation: A usage-based approach to bilingual speech production. International Journal of Bilingualism 19: 387-406. [CrossRef]

Bruyn, Adrienne, Pieter Muysken, and Maaike Verrips. 1999. Double object constructions in Creole languages. In Language Creation and Language Change. Creolization, Diachrony, and Development. Edited by Michel DeGraff. Cambridge: MIT Press, pp. 329-74.

Brysbaert, Marc, Goedele Van Dyck, and Marijke Van de Poel. 1999. Visual word recognition in bilinguals: Evidence from masked phonological priming. Journal of Experimental Psychology: Human Perception and Performance 25: 137-48. [CrossRef] [PubMed]

Bybee, Joan. 2010. Language, Usage and Cognition. Cambridge: Cambridge University Press. [CrossRef]

Cai, Zhenguang G., Martin J. Pickering, Hao Yan, and Holly P. Branigan. 2011. Lexical and syntactic representations in closely related languages: Evidence from Cantonese-Mandarin bilinguals. Journal of Memory and Language 65: 431-45. [CrossRef]

Campbell-Kibler, Kathryn. 2010. New Directions in Sociolinguistic Cognition. University of Pennsylvania Working Papers in Linguistics 15: 30-39.

Campbell-Kibler, Kathryn. 2016. Toward a cognitively realistic model of meaningful sociolinguistic variation. In Awareness and Control in Sociolinguistic Research. Edited by Anna M. Babel. Cambridge: Cambridge University Press, pp. 123-51.

Chang, Franklin, Gary S. Dell, and J. Kathryn Bock. 2006. Becoming syntactic. Psychological Review 113: 234. [CrossRef]

Clark, Eve Vivienne. 1978. Awareness of language: Some evidence from what children say and do. In The Child's Conception of Language. Edited by A. Sinclair, R. Jarvella and W. Levelt. New York: Springer Verlag, pp. 17-43. [CrossRef]

Cleland, Alexandra A., and Martin J. Pickering. 2003. The use of lexical and syntactic information in language production: Evidence from the priming of noun-phrase structure. Journal of Memory and Language 49: 214-30. [CrossRef]

Corley, Martin, and Christoph Scheepers. 2002. Syntactic priming in English sentence production: Categorical and latency evidence from an Internet-based study. Psychonomic Bulletin E Review 9: 126-31. [CrossRef] 
Coyle, Jacqueline M., and Michael P. Kaschak. 2008. Patterns of experience with verbs affect long-term cumulative structural priming. Psychonomic Bulletin \& Review 155: 967-70. [CrossRef]

Croft, William. 2000. Explaining Language Change: An Evolutionary Approach. London: Pearson Education.

de Bot, Kees, Wander Lowie, and Marjolijn Verspoor. 2007. A Dynamic Systems Theory approach to second language acquisition. Bilingualism: Language and Cognition 10: 7-21. [CrossRef]

Dell, Gary S., and Franklin Chang. 2014. The P-chain: Relating sentence production and its disorders to comprehension and acquisition. Phil. Trans. R. Soc. B 369: 20120394. [CrossRef] [PubMed]

Dell, Gary S., and Victor S. Ferreira. 2016. Thirty years of structural priming: An introduction to the special issue. Journal of Memory and Language 91: 1-4. [CrossRef]

Desmet, Timothy, and Mieke Declercq. 2006. Cross-linguistic priming of syntactic hierarchical configuration information. Journal of Memory and Language 54: 610-32. [CrossRef]

Dijksterhuis, Ap, and John A. Bargh. 2001. The perception-behavior expressway: Automatic effects of social perception on social behavior. In Advances in Experimental Social Psychology. Edited by M. P. Zanna. New York: Academic Press, vol. 33, pp. 1-40. [CrossRef]

Doğruöz, A. Seza, and Ad Backus. 2009. Innovative constructions in Dutch Turkish: An assessment of ongoing contact-induced change. Bilingualism: Language and Cognition 12: 41-63. [CrossRef]

Düzel, Emrah, Andrew P. Yonelinas, George R. Mangun, Hans-Jochen Heinze, and Endel Tulving. 1997. Event-related brain potential correlates of two states of conscious awareness in memory. Proceedings of the National Academy of Sciences 94: 5973-78. [CrossRef]

Eckert, Penelope. 2012. Three waves of variation study: The emergence of meaning in the study of sociolinguistic variation. Annual Review of Anthropology 41: 87-100. [CrossRef]

Ellis, N. C. 2015. Implicit AND Explicit Language Learning: Their dynamic interface and complexity. In Implicit and Explicit Learning of Languages. Edited by Patrick Rebuschat. Amsterdam: John Benjamins, pp. 3-23. [CrossRef]

Ferguson, Charles A. 1975. Toward a characterization of English foreigner talk. Anthropological Linguistics 17: 1-14.

Fernández, Eva M., Ricardo Augusto De Souza, and Agustina Carando. 2017. Bilingual innovations: Experimental evidence offers clues regarding the psycholinguistics of language change. Bilingualism: Language and Cognition 20: 251-68. [CrossRef]

Ferreira, Victor S. 1996. Is it better to give than to donate? Syntactic flexibility in language production. Journal of Memory and Language 35: 724-55. [CrossRef]

Ferreira, Victor S., and J. Kathryn Bock. 2006. The functions of structural priming. Language and Cognitive Processes 21: 1011-29. [CrossRef]

Ferreira, Victor S., J. Kathryn Bock, Michael P. Wilson, and Neal J. Cohen. 2008. Memory for syntax despite amnesia. Psychological Science 19: 940-46. [CrossRef]

Forster, Kenneth I. 1998. The pros and cons of masked priming. Journal of Psycholinguistic Research 27: $203-33$. [CrossRef]

Fox, Elaine. 1996. Cross-language priming from ignored words: Evidence for a common representational system in bilinguals. Journal of Memory and Language 35: 353-70. [CrossRef]

Fricke, Melinda, and Gerrit Jan Kootstra. 2016. Primed codeswitching in spontaneous bilingual dialogue. Journal of Memory and Language 91: 181-201. [CrossRef]

Frost, Ram, Avital Deutsch, Orna Gilboa, Michal Tannenbaum, and William Marslen-Wilson. 2000. Morphological priming: Dissociation of phonological, semantic, and morphological factors. Memory \& Cognition 28: 1277-88. [CrossRef]

Garrod, Simon, and Anthony Anderson. 1987. Saying what you mean in dialogue: A study in conceptual and semantic co-ordination. Cognition 27: 181-218. [CrossRef]

Garrod, Simon, and Martin J. Pickering. 2004. Why is conversation so easy? Trends in Cognitive Sciences 8: 8-11. [CrossRef] [PubMed]

Garrod, Simon, and Martin J. Pickering. 2007. Alignment in dialogue. In The Oxford Handbook of Psycholinguistics. Edited by Gareth Gaskell. Oxford: Oxford University Press, pp. 443-51. [CrossRef]

Garrod, Simon, and Martin J. Pickering. 2013. Dialogue: Interactive alignment and its implications for language learning and language change. In The Language Phenomenon. Edited by P. -M. Binder and K. Smith. Berlin and Heidelberg: Springer, pp. 47-64. [CrossRef] 
Giles, Howard, Justine Coupland, and Nicolas Coupland. 1991. Accommodation Theory: Communication, Context, and Consequence. In Contexts of Accommodation. Edited by Howard Giles, Justine Coupland and Nicolas Coupland. New York: Cambridge University Press. [CrossRef]

Grice, Paul. 1975. Logic and conversation. In Syntax and Semantics. 3: Speech Acts. Edited by Peter Cole and Jerry Morgan. New York: Academic Press, pp. 41-58.

Gries, Stefan Th., and Gerrit Jan Kootstra. 2017. Structural priming within and across languages: A corpus-based perspective. Bilingualism: Language and Cognition 20: 235-50. [CrossRef]

Gries, Stefan Th., and Anatol Stefanowitsch. 2004. Extending collostructional analysis: A corpus-based perspective on "alternations". International Journal of Corpus Linguistics 9: 97-129. [CrossRef]

Hartsuiker, Robert J., and Sarah Bernolet. 2017. The development of shared syntax in second language learning. Bilingualism: Language and Cognition 20: 219-34. [CrossRef]

Hartsuiker, Robert J., and Martin J. Pickering. 2008. Language integration in bilingual sentence production. Acta Psychologica 128: 479-89. [CrossRef] [PubMed]

Hartsuiker, Robert J., Martin J. Pickering, and Eline Veltkamp. 2004. Is syntax separate or shared between languages? Cross-linguistic syntactic priming in Spanish/English bilinguals. Psychological Science 15: 409-14. [CrossRef] [PubMed]

Hartsuiker, Robert J., Sarah Bernolet, Sofie Schoonbaert, Sarah Speybroeck, and Dieter Vanderelst. 2008. Syntactic priming persists while the lexical boost decays: Evidence from written and spoken dialogue. Journal of Memory and Language 58: 214-38. [CrossRef]

Hartsuiker, Robert J., Saskia Beerts, Maaike Loncke, Timothy Desmet, and Sarah Bernolet. 2016. Cross-linguistic structural priming in multilinguals: Further evidence for shared syntax. Journal of Memory and Language 90: 14-30. [CrossRef]

Indefrey, Peter, Hülya Şahin, and Marianne Gullberg. 2017. The expression of spatial relationships in Turkish-Dutch bilinguals. Bilingualism: Language and Cognition 20: 473-93. [CrossRef]

Jacob, Gunnar. 2018. Morphological priming in bilingualism research. Bilingualism: Language and Cognition 21: 443-47. [CrossRef]

Jacob, Gunnar, Kalliopi Katsika, Neiloufar Family, and Shanley E. M. Allen. 2017. The role of constituent order and level of embedding in cross-linguistic structural priming. Bilingualism 20: 269-82. [CrossRef]

Jacoby, Larry L. 1991. A process dissociation framework: Separating automatic from intentional uses of memory. Journal of Memory and Language 305: 513-41. [CrossRef]

Jaeger, T. Florian, and Neal Snider. 2007. Implicit learning and syntactic persistence: Surprisal and cumulativity. University of Rochester Working Papers in the Language Sciences 3: 26-44.

Jaeger, T. Florian, and Neal Snider. 2013. Alignment as a consequence of expectation adaptation: Syntactic priming is affected by the prime's prediction error given both prior and recent experience. Cognition 127: 57-83. [CrossRef] [PubMed]

Jaeger, T. Florian, and Kodi Weatherholtz. 2016. What the heck is salience? How predictive language processing contributes to sociolinguistic perception. Frontiers in Psychology 7. [CrossRef] [PubMed]

Jäger, Gerhard, and Anette Rosenbach. 2008. Priming and unidirectional language change. Theoretical linguistics 34: 85-113. [CrossRef]

Kang, Olivia, and Thalia Wheatley. 2015. Pupil dilation patterns reflect the contents of consciousness. Consciousness and Cognition 35: 128-35. [CrossRef] [PubMed]

Kantola, Leila, and Roger P. G. van Gompel. 2011. Between- and within-language priming is the same: Evidence for shared bilingual syntactic representations. Memory $\mathcal{E}$ Cognition 39: 276-90. [CrossRef]

Kaschak, Michael P. 2007. Long-term structural priming affects subsequent patterns of language production. Memory \& Cognition 35: 925-37. [CrossRef]

Kaschak, Michael P., Timothy J. Kutta, and Christopher Schatschneider. 2011. Long-term cumulative structural priming persists for (at least) one week. Memory $\mathcal{E}$ Cognition 39: 381-88. [CrossRef]

Kaschak, Michael P., Timothy J. Kutta, and Jacqueline M. Coyle. 2012. Long and short term cumulative structural priming effects. Language, Cognition and Neuroscience 29: 728-43. [CrossRef] [PubMed]

Kidd, Evan, Emilie Tennant, and Sanjo Nitschke. 2015. Shared abstract representation of linguistic structure in bilingual sentence comprehension. Psychonomic Bulletin \& Review 22: 1062-67. [CrossRef] 
Kootstra, Gerrit Jan, and Willemijn J. Doedens. 2016. How multiple sources of experience influence bilingual syntactic choice: Immediate and cumulative cross-language effects of structural priming, verb bias, and language dominance. Bilingualism: Language and Cognition 19: 710-32. [CrossRef]

Kootstra, Gerrit Jan, and Pieter C. Muysken. 2017. Cross-linguistic priming in bilinguals: Multidisciplinary perspectives on language processing, acquisition, and change. (Introduction to special issue). Bilingualism: Language and Cognition 20: 215-18. [CrossRef]

Kootstra, Gerrit Jan, and Hülya Şahin. 2018. Cross-linguistic structural priming as a mechanism of contact-induced language change: Evidence from Papiamento-Dutch bilinguals in Aruba and the Netherlands. Language 94: 902-30. [CrossRef]

Kroll, Judith F., Susan C. Bobb, and Zofia Wodniecka. 2006. Language selectivity is the exception, not the rule: Arguments against a fixed locus of language selection in bilingual speech. Bilingualism: Language and Cognition 9: 119-35. [CrossRef]

Labov, William. 1972. Sociolinguistic Patterns. Philadelphia: University of Pennsylvania Press.

Labov, William. 2007. Transmission and Diffusion. Language 83: 344-87. [CrossRef]

Levelt, Willem J. M. 1989. Speaking: From Intention to Articulation. Cambridge: Cambridge University Press.

Loebell, Helga, and J. Kathryn Bock. 2003. Structural priming across languages. Linguistics 41: 791-824. [CrossRef]

Lucas, Margery. 2000. Semantic priming without association: A meta-analytic review. Psychonomic Bulletin $\mathcal{E}$ Review 7: 618-30. [CrossRef]

Luk, J. 2013. Bilingual language play and local creativity in Hong Kong. International Journal of Multilingualism 10: 236-50. [CrossRef]

MacDonald, Maryellen C. 2013. How language production shapes language form and comprehension. Frontiers in Psychology 4: 226. [CrossRef] [PubMed]

MacLeod, Bethany. 2015. A critical evaluation of two approaches to defining perceptual salience. Ampersand 2: 83-92. [CrossRef]

Mahowald, Kyle, Ariel James, Richard Futrell, and Edward Gibson. 2016. A meta-analysis of syntactic priming in language production. Journal of Memory and Language 91: 5-27. [CrossRef]

Melloni, Lucia, Caspar M. Schwiedrzik, Notger Muller, Eugenio Rodriguez, and Wolf Singer. 2011. Expectations Change the Signatures and Timing of Electrophysiological Correlates of Perceptual Awareness. Journal of Neuroscience 31: 1386-96. [CrossRef] [PubMed]

Mendoza-Denton, Norma. 2002. Language and Identity. In The Handbook of Language Variation and Change. Edited by J. K. Chambers, Peter Trudgill and Natalie Schilling-Estes. Oxford: Blackwell, pp. 475-99. [CrossRef]

Moro, Francesca, and Marian Klamer. 2015. Give-constructions in heritage Ambon Malay in the Netherlands. Journal of Language Contact 8: 263-98. [CrossRef]

Otheguy, Ricardo, Ana Celia Zentella, and David Livert. 2007. Language and dialect contact in Spanish in New York: Toward the formation of a speech community. Language 83: 770-802. [CrossRef]

Pardo, Jennifer S. 2006. On phonetic convergence during conversational interaction. The Journal of the Acoustical Society of America 119: 2382-93. [CrossRef]

Pickering, Martin J., and Holly P. Branigan. 1999. Syntactic priming in language production. Trends in Cognitive Sciences 3: 136-41. [CrossRef]

Pickering, Martin J., and Victor S. Ferreira. 2008. Structural priming: A critical review. Psychological Bulletin 134: 427-59. [CrossRef]

Pickering, Martin J., and Simon Garrod. 2004. Toward a mechanistic psychology of dialogue. Behavioral and Brain Sciences 27: 169-90. [CrossRef]

Rivlina, Alexandra. 2015. Bilingual creativity in Russia: English-Russian language play. World Englishes 34: 436-55. [CrossRef]

Salamoura, Angeliki, and John N. Williams. 2006. Lexical activation of cross-language syntactic priming. Bilingualism: Language and Cognition 9: 299-307. [CrossRef]

Scheepers, Christoph, Claudine N. Raffray, and Andriy Myachykov. 2017. The lexical boost effect is not diagnostic of lexically-specific syntactic representations. Journal of Memory and Language 95: 102-15. [CrossRef]

Scherre, Maria M. P., and Anthony J. Naro. 1991. Marking in discourse: "Birds of a feather". Language Variation and Change 3: 23-32. [CrossRef]

Schmidt, Richard W. 1990. The role of consciousness in second language learning. Applied Linguistics 11: 129-58. [CrossRef] 
Schoonbaert, Sofie, Robert J. Hartsuiker, and Martin J. Pickering. 2007. The representation of lexical and syntactic information in bilinguals: Evidence from syntactic priming. Journal of Memory and Language 56: 153-71. [CrossRef]

Schütz-Bosbach, Simone, and Wolfgang Prinz. 2007. Perceptual resonance: Action-induced modulation of perception. Trends in Cognitive Sciences 11: 349-55. [CrossRef] [PubMed]

Searle, John R. 1969. Speech Acts: An Essay in the Philosophy of Language. Cambridge: Cambridge University Press, vol. 626. [CrossRef]

Shin, Jeong-Ah, and Kiel Christianson. 2009. Syntactic processing in Korean-English bilingual production: Evidence from cross-linguistic structural priming. Cognition 112: 175-80. [CrossRef]

Shin, Jeong-Ah, and Kiel Christianson. 2012. Structural Priming and Second Language Learning. Language Learning 62: 931-64. [CrossRef]

Silverstein, Michael. 1981. The limits of awareness. In Working Papers in Sociolinguistics. Austin: Southwest Educational Development Laboratory.

Sodac1, Hande, Ad Backus, and Gerrit Jan Kootstra. 2019. Role of structural priming in contact-induced change: Subject pronoun expression in L1 Turkish by Turkish-Dutch bilinguals. PsyArchiv. [CrossRef]

Sportiche, Dominique, Hilda Koopman, and Edward Stabler. 2014. An Introduction to Syntactic Analysis. West Sussex: Wiley Blackwell.

Tarone, Elaine. 1980. Communication strategies, foreigner talk, and repair in interlanguage. Language Learning 30: 417-28. [CrossRef]

Thomason, Sarah Grey. 2006. Language Change, intentional. In Encyclopedia of Language and Linguistics, 2nd ed. Edited by Keith Brown. Abingdon-on-Thames: Routledge, vol. 6, pp. 346-49. [CrossRef]

Thomason, Sarah, and Terrence Kaufman. 1988. Language Contact, Creolization, and Genetic Linguistics. Berkeley: University of California Press.

Tomasello, Michael. 2003. Constructing a Language: A Usage-Based Approach to Child Language Acquisition. Cambridge: Harvard University Press.

Tooley, Kristen M., Matthew Traxler, and Tamara Y. Swaab. 2009. Electrophysiological and behavioral evidence of syntactic priming in sentence comprehension. Journal of Experimental Psychology. Learning, Memory, and Cognition 35: 19-45. [CrossRef] [PubMed]

Torres Cacoullos, Rena, and Catherine E. Travis. 2010. Testing convergence via code-switching: Priming and the structure of variable subject expression. International Journal of Bilingualism 15: 241-67. [CrossRef]

Travis, Catherine E., Rena Torres Cacoullos, and Evan Kidd. 2017. Cross-language priming: A view from bilingual speech. Bilingualism: Language and Cognition 20: 283-98. [CrossRef]

Trofimovich, Pavel, and Sara Kennedy. 2014. Interactive alignment between bilingual interlocutors: Evidence from two information-exchange tasks. Bilingualism: Language and Cognition 17: 822-36. [CrossRef]

Trudgill, Peter. 1981. Linguistic accommodation: Sociolinguistic observations on a sociopsychological theory. In Papers from the Parasession on Language and Behavior. Edited by Carrie S. Masek, Roberta A. Hendrick and Mary Frances Miller. Chicago: University of Chicago Press, pp. 218-37.

Trudgill, Peter. 1986. Dialects in Contact. Oxford: Blackwell.

Tsiplakou, Stavroula. 2009. Doing (bi)lingualism: Language alternation as performative construction of online identities. Pragmatics 19: 361-91. [CrossRef]

van Baaren, Rick B., R. W. Holland, B. Steenaert, and A. van Knippenberg. 2003. Mimicry for money: Behavioral consequences of imitation. Journal of Experimental Social Psychology 39: 393-98. [CrossRef]

Van Coetsem, Frans. 1988. Loan Phonology and the Two Transfer Types in Language Contact. Publications in language sciences 27. Dordrecht: Foris Publications. [CrossRef]

Van Coetsem, Frans. 1995. Outlining a model of the transmission phenomenon in language contact. Leuvense Bijdragen 84: 63-85.

van de Meerendonk, Nan, Herman H. J. Kolk, Dorothee J. Chwilla, and Constance Th. W. M. Vissers. 2009. Monitoring in Language Perception. Language and Linguistics Compass 3: 1211-24. [CrossRef]

van Gompel, Roger P. G., and Manabu Arai. 2018. Structural priming in bilinguals. Bilingualism: Language and Cognition 21: 448-55. [CrossRef]

Van Hell, Janet G., and Ton Dijkstra. 2002. Foreign language knowledge can influence native language performance in exclusively native contexts. Psychonomic Bulletin $\mathcal{E}$ Review 9: 780-89. [CrossRef] 
van Hell, Janet G., and Darren Tanner. 2012. Second language proficiency and cross-language lexical activation. Language Learning 62: 148-71. [CrossRef]

Van Heuven, Walter J. B., Ton Dijkstra, Jonathan Grainger, and Herbert Schriefers. 2001. Shared neighborhood effects in masked orthographic priming. Psychonomic Bulletin E Review 8: 96-101. [CrossRef]

Verschik, A. 2017. Language Contact, Language Awareness, and Multilingualism. In Language Awareness and Multilingualism, Encyclopedia of Language and Education, 3rd ed. Edited by Jasone Cenoz, Durk Gorter and Stephen May. Cham: Springer. [CrossRef]

Villerius, Sofie. 2019. Development of Surinamese Javanese: Language Contact and Change in a Multilingual Context. Doctoral dissertation, Radboud University, Nijmegen, The Netherlands.

von Humboldt, Wilhelm. 1836. The Heterogeneity of Language and Its Influence on the Intellectual Development of Mankind (orig. Ueber die Verschiedenheit des menschlichen Sprachbaus und ihren Einfluss auf die geistige Entwicklung des Menschengeschlechts), 2nd ed. New edition: On Language. On the Diversity of Human Language Construction and Its Influence on the Mental Development of the Human Species. Cambridge: Cambridge University Press.

Weber, Kirsten, and Peter Indefrey. 2009. Syntactic priming in German-English bilinguals during sentence comprehension. NeuroImage 46: 1164-72. [CrossRef] [PubMed]

Weiner, E. Judith, and William Labov. 1983. Constraints on the agentless passive. Journal of Linguistics 19: 29-58. [CrossRef]

Weinreich, Uriel. 1953. Languages in Contact: Findings and Problems. New York: Linguistic Circle of New York. [CrossRef]

Weinreich, Uriel, William Labov, and Marvin I. Herzog. 1968. Empirical foundations for a theory of language change. In Directions for Historical Linguistics. Edited by W. P. Lehmann and Y. Malkiel. Austin: University of Texas Press, pp. 95-195.

Whorf, Benjamin. 1956. Language, Thought, and Reality: Selected Writings of Benjamin Lee Whorf. Edited by John B. Carroll. Cambridge: MIT Press.

(C) 2019 by the authors. Licensee MDPI, Basel, Switzerland. This article is an open access article distributed under the terms and conditions of the Creative Commons Attribution (CC BY) license (http://creativecommons.org/licenses/by/4.0/). 